\title{
Surface Potential Distribution on the Human Thoracic Surface in Left Bundle Branch Block
}

\author{
István PRÉda, M.D., István BukoszA, M.D., György Kozmann, \\ Dipl. Eng.," Vsevolod V. Shakin, Ph.D., "* Ádám Székely, M.D., \\ and Zoltán Antalóczy, M.D.
}

\section{Summary}

The sequences of myocardial excitation in the cases of human LBBB have been studied by the surface mapping technique. Analysis of the surface map patterns of 12 subjects has enabled 4 different types to be described.

It is suggested that Type I represents a complete LBBB in the presence of an intact right bundle branch, while Types II and III show different degrees of conduction defect in the right bundle branch, too. The left ventricular activation of these 3 types has a similar pathway in phases II and III which is determined by orientation of the main subepicardial muscle layer coursing through the apex and terminating in the anterobasal region.

The terminal anterobasal activation in the cases of LBBB has not only theoretical, but clinical significance, since in the presence of anteroseptal myocardial infarction the signs of necrosis must be hidden not in the early, but in the terminal parts of the QRS complex of conventional EGG.

The lack of terminal anterior positivity of surface maps in the case of LBBB may be indicative of chronic anterior myocardial infarction.

\section{Additional Indexing Words :}

Electrocardiogram Activation sequence Myocardial infarction Conduction disturbances

TVER since the first experiment by Eppinger and Rothberger ${ }^{5}$ ) on the 1 effect of interruption of the bundle branches on the electrocardiogram, several hypotheses have been proposed ${ }^{10), 15), 23), 24)}$ for the elucidation of the genetic mechanism of the electrocardiographic pattern of left bundle branch block (LBBB). This confusion has partly been due to the extrapolation of the results of acute animal experiments and partly to the findings in chronically affected human hearts. ${ }^{2)}$ Rodriguez and Sodi-Pallares ${ }^{15)}$ concluded that in

\footnotetext{
From the Second Medical Clinic, Postgraduate Medical School, 1389 Budapest, POB 112, Hungary, Central Research Institute for Physics, Budapest, Hungary*, and Institute for Information Transmission Problems, Moscow, USSR**.

Address for reprint: István Préda, M.D., 2nd Medical Clinic of Postgraduate Medical School, 1389, Budapest, POB 112, Hungary.

Received for publication May 8, 1978.
} 
bundle branch block most of the time-delay in activation of the contralateral ventricle was due to a "barrier" between the right and left ventricular parts of the interventicular septum, and also that the activation process, once having passed the septum, was carried further in an almost normal way by the peripheral part of the affected bundle branch. However, these results seemed questionable from the outset, and have not been confirmed by other research workers. ${ }^{1,6)}$ New techniques for the better understanding of the activation process in experimentally induced chronic bundle branch blocks were designed by van $\mathrm{Dam}^{2)}$ and his results strongly suggested an exclusively myocardial conduction during almost the entire ventricular activation in LBBB and he found no evidence of the septal "barrier" mechanism.

Myocardial infarction may cause LBBB or it may be superimposed upon an existing LBBB. The question has both theoretical and clinical significance since LBBB radically alters the sequences of ventricular activation and in its presence it is seldom possible to make a diagnosis of myocardial infarction on the basis of conventional electrocardiographic findings alone. ${ }^{16)}$ In the last few years attempts have been made to characterize potential distributions over the chest surface in intraventricular conduction distrubances like the Wolff-Parkinson-White syndrome ${ }^{3), 22), 25)}$ and the right bundle branch block, ${ }^{12,18), 21,27)}$ but no literature is available on the clinical investigation of LBBB by body surface isopotential mapping.

\section{METHOD}

Twelve cardiac patients suffering from $\mathrm{LBBB}$ with no history of acute myocardial infarction were studied. First the standard 12-lead electrocardiogram (ECG) and the Frank orthogonal leads were recorded. For the construction of body surface isopotential maps (surface maps), 138 unipolar lead ECGs consisting of 90 points distributed over the anterior chest surface and 48 points distributed over

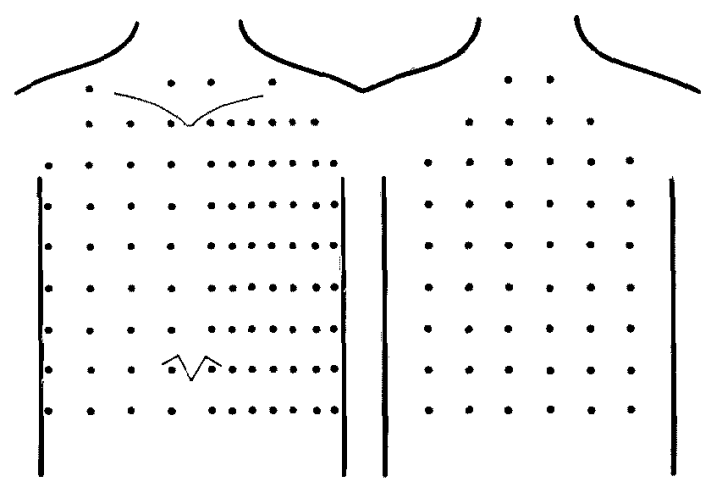

Fig. I. Schematic representation of distribution of electrodes over anterior (left side) and posterior (right side) chest surface. 
the back (Fig. 1) were registered on a 4-channel magnetic tape recorder (Racal Store-4) synchronously with the standard lead II electrocardiogram as a time reference. ${ }^{7}$ Following $\mathrm{A} / \mathrm{D}$ conversion, the recorded data were processed by a small computer (Videoton R-10), and the original values of the surface maps were printed in tabular form by the computer for every $2.5 \mathrm{msec}$ during the QRS interval; the equipotential lines were drawn manually. Each surface map illustrates the distribution of isopotential lines over the chest surface at a given time instant.

\section{Rseults}

In the present investigation, the surface maps recorded from the 12 patients with LBBB were grouped into 4 types (types I-IV) by analyzing characteristic patterns of potential distribution at different stages of ventricular excitation. Van $\mathrm{Dam}^{2)}$ suggested 3 phases in ventricular activation during complete bundle branch blocks. This suggestion was used for the interpretation of surface maps.

Phase I: activation of the "unaffected" right ventricle and excitation of the interventricular septum,

Phase II: Spread of activation in the posterior and lateral wall across the interventricular septum, continued septal activation,

Phase III: activation of the anterobasal part of the left ventricle.

Type I:

Five subjects were labelled Type 1. Fig. 2 illustrates the standard 12lead EGG of a representative patient of Type 1; Fig. 3 shows the time course of Type 1 surface map patterns. The schematic representation of the QRS complex of the $V_{1}$ ECG lead is shown in the upper left corner of the figure expressing the serial maps. The shaded areas illustrate the positive, the empty areas the negative zones; solid lines in each zone represent isopotential lines for each $0.5 \mathrm{mV}$, and the broken line stands for the potentials of Wilson's central terminal, called zero line.

During phase I ( 0 to $+50 \mathrm{msec})$, at the onset of ventricular activation a potential maximum appeared in the midsternal region. This phenomenon coincided temporally with the normal septal excitation which was maintained in this type of surface map and which occurred in a predominantly left-toright direction.4),19) Later, the minimum moved toward the right clavicular area, while the maximum moved downward and to the left. Fig. 3B shows characteristic pattern of "saddle" formation ${ }^{20)}$ considered to be the surface reflection of right ventricular breakthrough. The following surface maps corresponding to phase II $(+50$ to $+100 \mathrm{msec})$, show a broad anterior minimum increasing in both voltage and area, and separated maxima on the back and on the left lower border of the anterior chest wall, probably indicating 


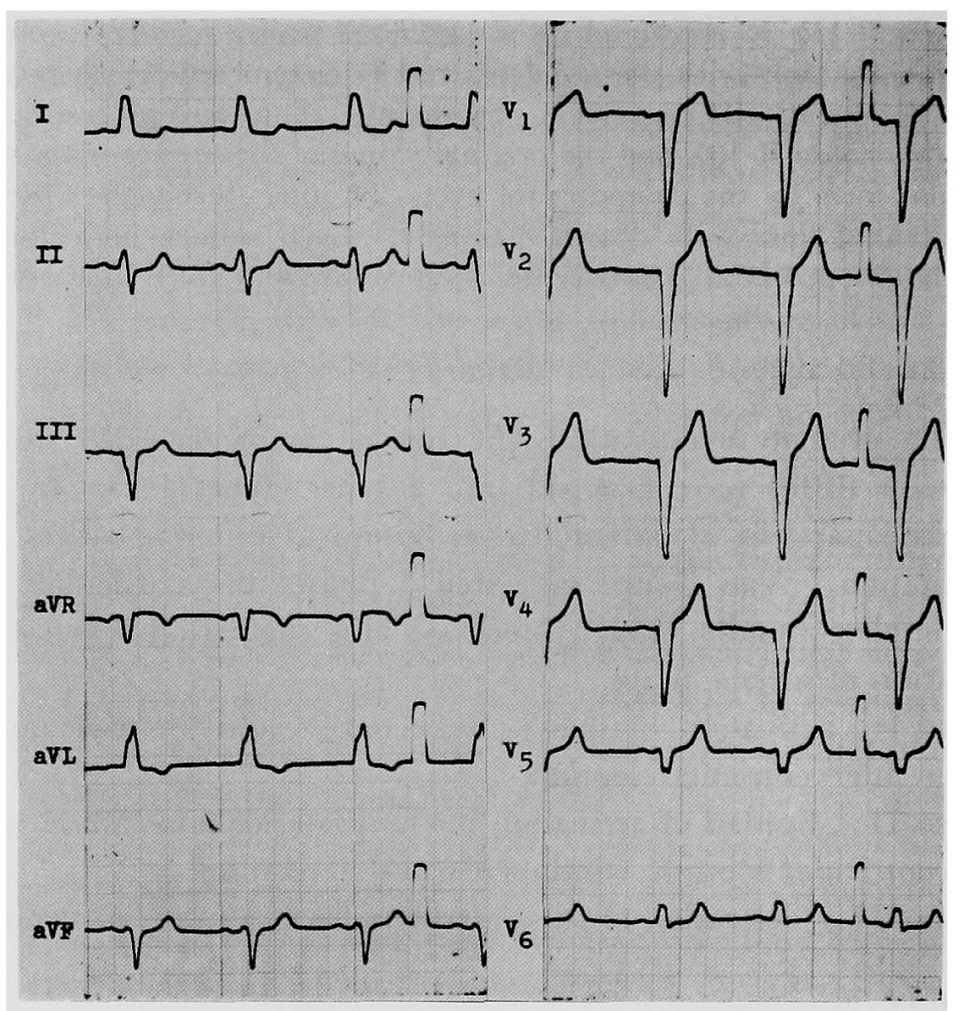

Fig. 2. Standard 12-lead ECG of a representative patient of Type I LBBB.
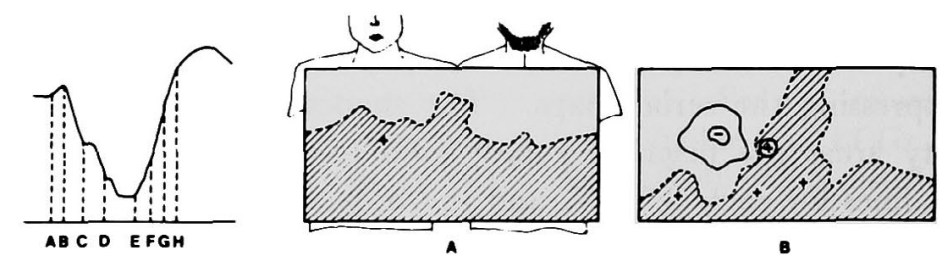

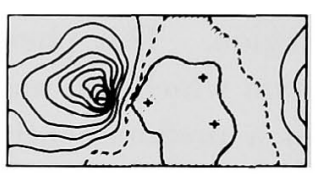

c

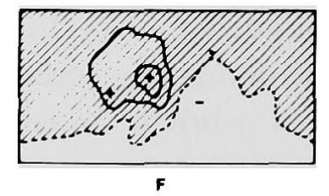

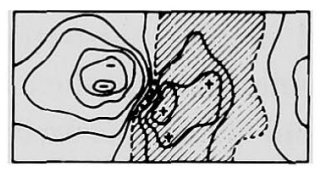

D

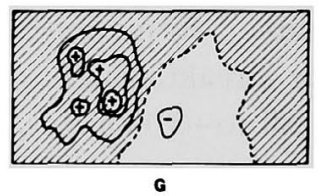

Fig. 3 .
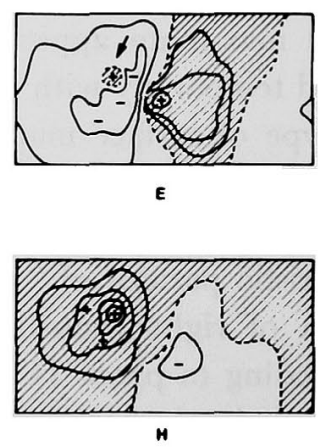
the gradual depolarization of the right ventricle and the posteroseptal directions of the left ventricular activation. Corresponding to these hypothetical directions of ventricular activation at this time, 2 minima were subsequently found on the anterior chest surface opposite to 3 maxima and these gradually melt into 1 maximum and move towards the left lateral border of the chest showing a clockwise rotation of left ventricular activation. Phase III $(+100$ to $+160 \mathrm{msec}$ ) commences with the distribution of potentials shown in Fig. $3 \mathrm{E}$, which points to the initiation of the excitation of the anterobasal area of the left ventricle indicated by an arrow in the figure; thus a new maximum appears in the midsternal region still surrounded by the negative zone. The terminal surface patterns of this type show the gradual activation of the remaining anterobasal region with an increasing anterior positivity, while the posterior and lateral negativity shows a still definitely depolarized area. The conventional 12-lead ECG exhibits at the same time in the precordial $\mathrm{V}_{1}-\mathrm{V}_{3}$ leads an upright $\mathrm{S}$ wave with an overshoot of potentials in the positive direction indicating the terminal depolarization forces directed from posterior to anterior.

\section{Type II:}

Four subjects were labelled Type II. The conventional 12 lead ECG of this type is shown in Fig. 4 and the serial surface maps are presented in Fig. 5. It is easy to recognize that at the onset of ventricular excitation (phase I) the early activation wavefront was directed to a lower part in the midline of the anterior chest surface and, similarly, the potential distribution of right ventricular breakthrough was also found lower (Fig. 5B), corresponding to the apical region of the right ventricle. On the same map the multiple maxima may be due to a fragmentation of the early right ventricular excitation waves, which probably indicates the existence of a conduction defect in the right bundle branch too. Later on (phase II), the serial maps indicate that the left ventricular activation is directed to the apex of the left ventricle, and from the apex to the lateral and posterobasal region. Fig. $5 \mathrm{E}$ shows that the activation of the anterobasal area is initiated from the lateral wall of the left ventricle (phase III) and thus in the terminal stages of ventricular excitation the anterior positivity is augmented in voltage.

- Fig. 3. Representative time course of Type I LBBB surface map patterns. The schematic drawing of the QRS complex of the $V_{1}$ ECG lead is shown in the upper left corner of the figure. The shaded areas illustrate the positive, the empty areas the ncgative zones; fine solid lines in each zone represent isopotential lines for each $0.5 \mathrm{mV}$, and the broken line stands for the zero potential (for explanation: see text). 


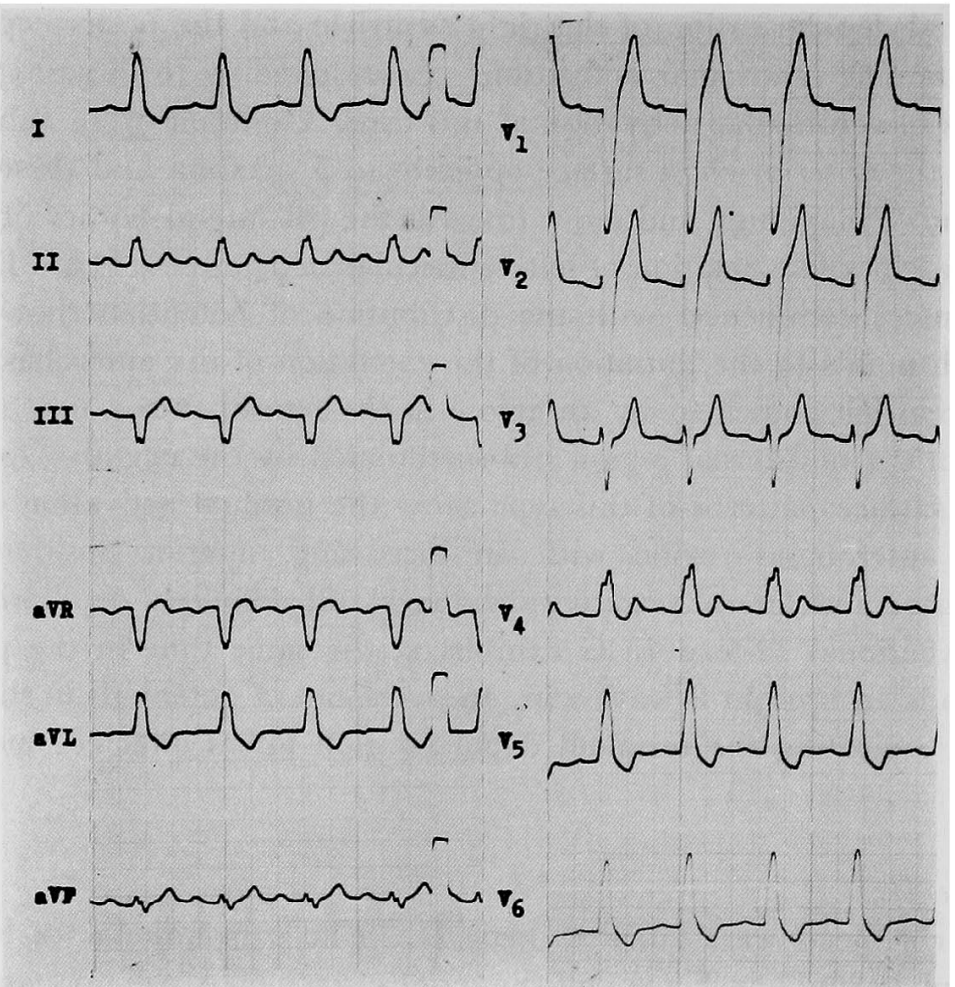

Fig. 4. Standard 12-lead ECG of a representative patient of Type II LBBB.
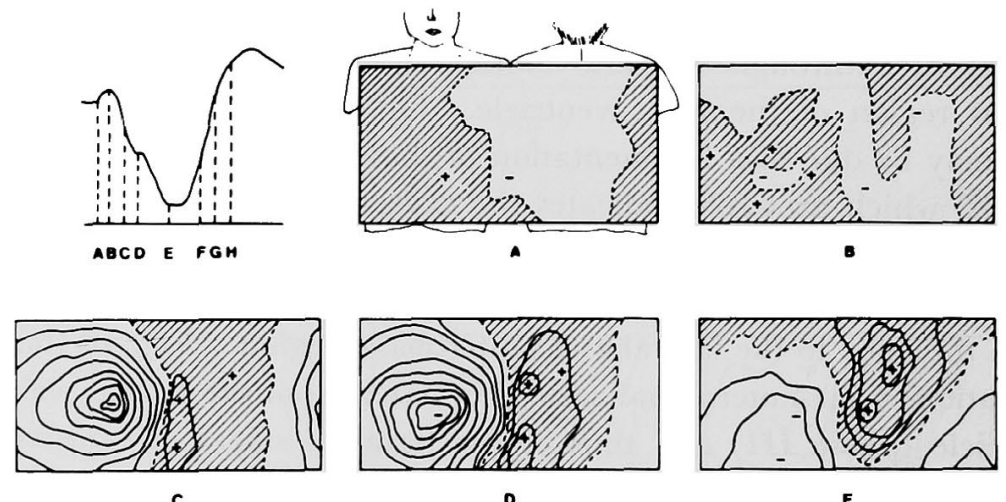

D

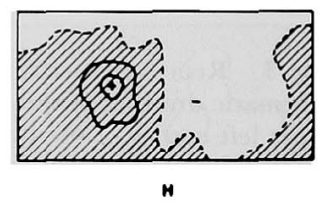

Fig. 5. 
Type III:

Type III was represented by 2 patients. The conventional ECG of one of these subjects is shown in Figs. 6 and 7 represents the surface map patterns of this type. A special characteristic of both cases is that the initial direction of ventricular activation (phase I) points towards the posteriorinferior segment of the ventricular septum, and that the initial negativity is located on the anterior chest surface. The right ventricular breakthrough, shown in Fig. 7B, is seen to arrive from the lateral surface of the right ventricle instead of the right supraclavicular region. The main direction of the left ventricular activation (phase II) reflected on the serial maps is similar to that of type II maps, thus the excitation waves travel through the left ventricular apex; after this the ventricular excitation reaches the lateral wall of the left ventricle and the posterobasal region. The terminal ventricular activation forces (phase III) reach the anterobasal region from the lateral wall (indicated by an arrow in Fig. 7F), and excite the remaining parts of the left anterior ventricular wall.

\section{Type IV:}

Type IV was represented by a single patient. The conventional ECG of this type of LBBB (Fig. 8) is quite unusual in that it shows a right axis deviation in the frontal plane. The serial surface maps of the same patient are depicted in Fig. 9. As shown in this figure, the initial activation wavefront (phase I) is directed towards the apex, and the potential distribution of right ventricular breakthrough was found in the same place (Fig. 9B). The main direction of left ventricular activation (phase II) points to the apex and to the diaphragmatic region (Fig. 9G); later on, the activation of the right and left ventricle seems to be somehow concentric and continuous as is reflected on the serial maps (Fig. 9D-F). The terminal excitation wavefronts (phase III) of this type were directed towards the postero-septal region and toward the right ventricular outflow tract. ${ }^{17}$

\section{Discussion}

By taking into consideration of the location of potential maxima and minima occurring during the depolarization in our 12 LBBB patients, we are

- Fig. 5. Representative time course of Type II LBBB surface map patterns. The schematic drawing of the QRS complex of the $V_{1}$ ECG lead is shown in the upper left corner of the figure. The shaded areas illustrate the positive, the empty areas the negative zones; fine solid lines in each zone respresent isopotential lines for each $0.5 \mathrm{mV}$, and the broken line stands for the zero potential (for explanation: see text). 

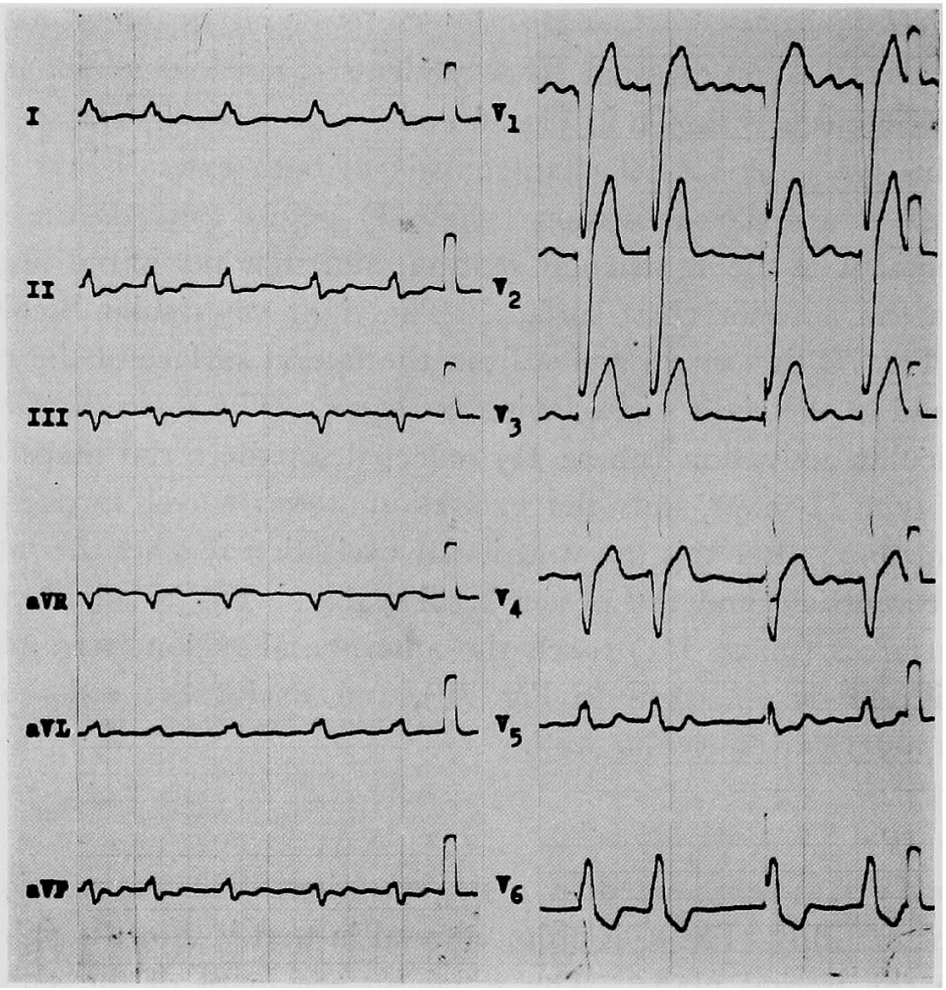

Fig. 6. Standard 12-lead ECG of a representative patient of Type III LBBB.
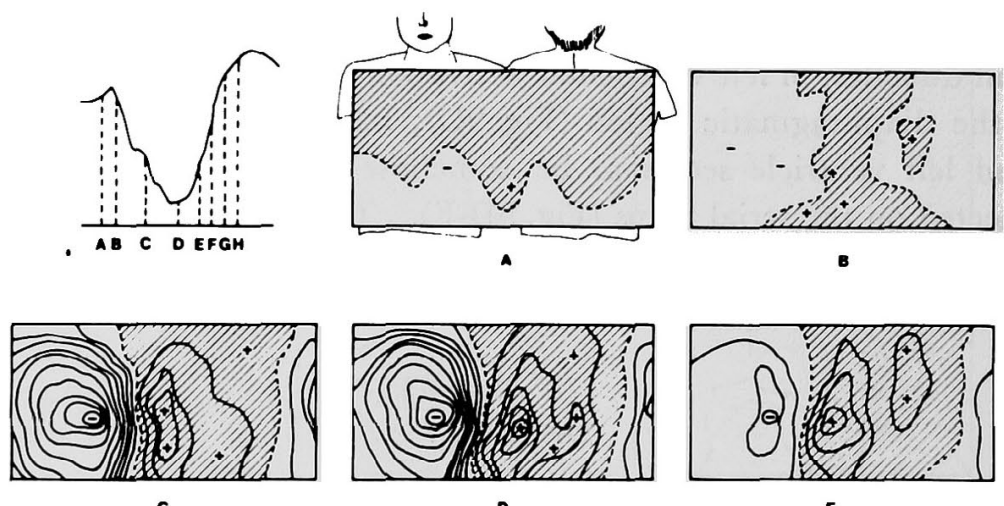

D

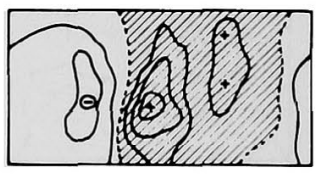

E
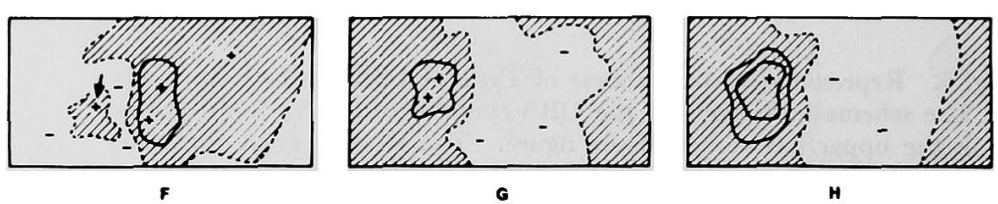

Fig. 7 . 


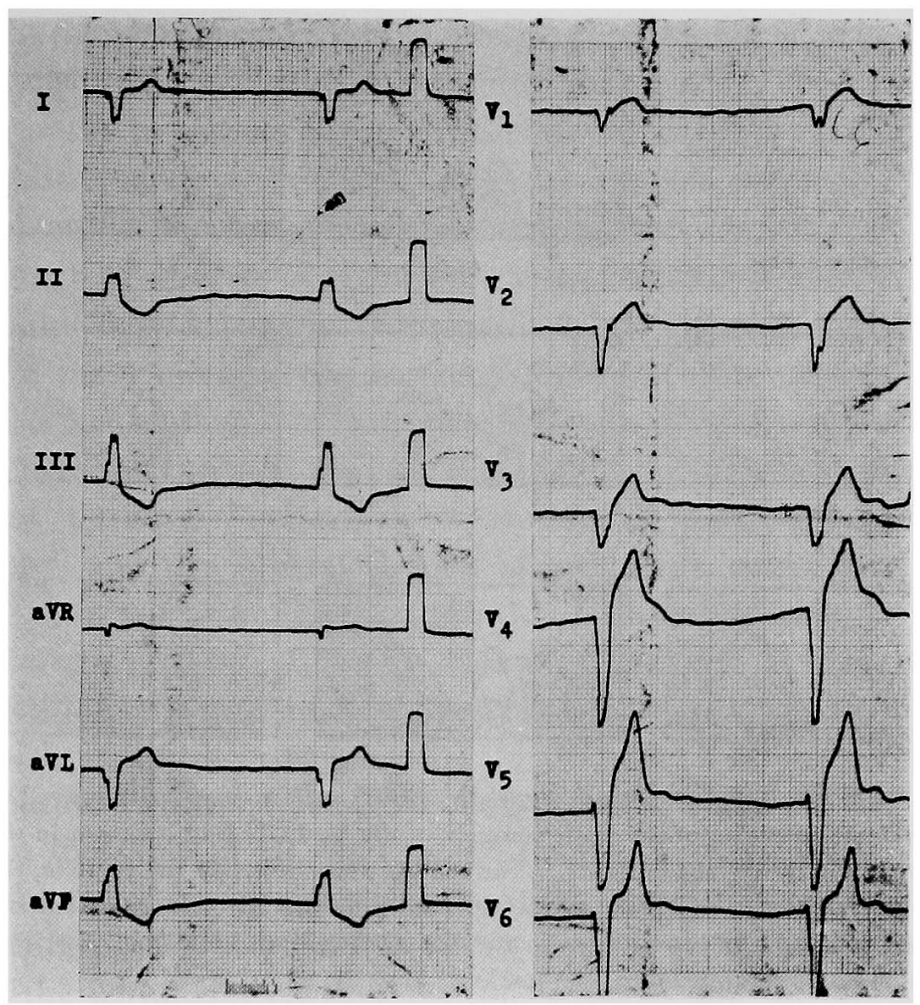

Fig. 8. Conventional 12-lead ECG of Type IV LBBB patient.

able to distinguish 4 different types of this intraventricular conduction defect. We are aware that since our grouping is based on a limited number of cases it certainly does not include all the possible cases. Even so, this study shows that body surface maps provide more information on the probable activation sequences of LBBB than is obtainable from the 12 lead EGG.

By analyzing the different types of maps it is possible to draw the first conclusion that the maps of Type I, Type II, and Type III are mainly similar to each other in phases II and III and the characteristic differences between them are manifested in phase I which represents the activation of the "unaffected" right ventricle and the excitation of the interventricular septum. The surface map patterns observed in the initial phase of ventricular activa-

- Fig. 7. Time course of Type III LBBB surface map patterns. The schematic drawing of the QRS complex of the $V_{1}$ ECG lead is shown in the upper left corner of the figure. The shaded areas illustrate the positive, the empty areas the negative zones; fine solid lines in each zone represent isopotential lines for each $0.5 \mathrm{mV}$, and the broken line stands for the zero potential (for explanation: see text). 

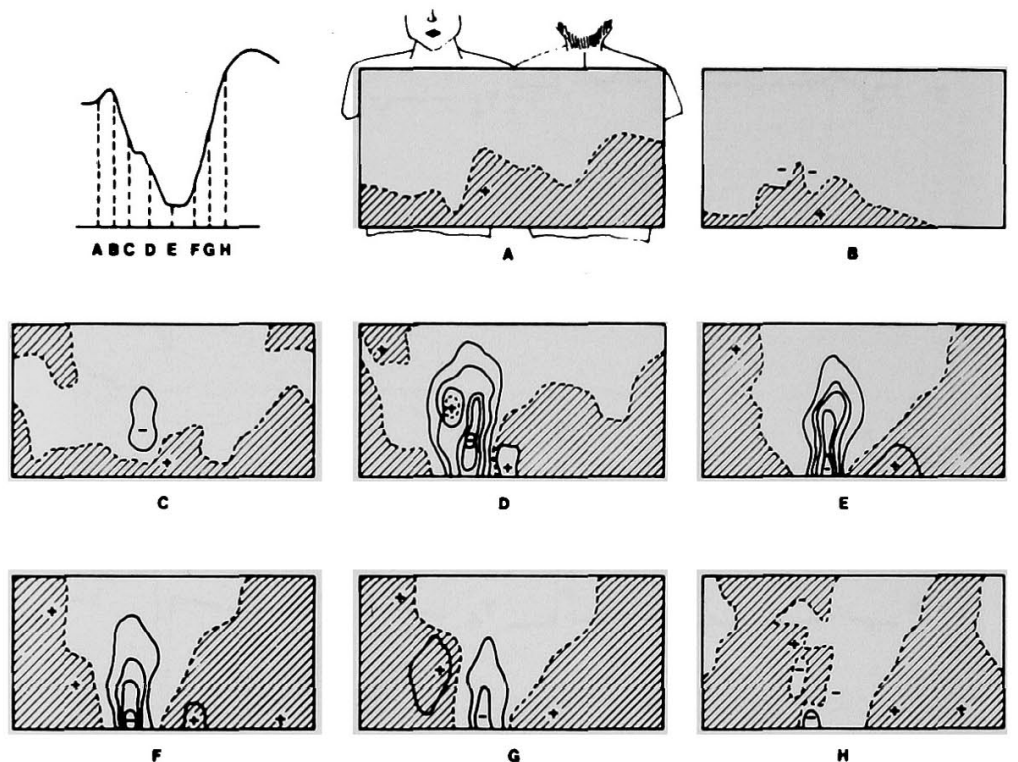

Fig. 9. Time course of Type IV LBBB surface map patterns. The schematic drawing of the QRS complex of the $V_{1}$ ECG lead is shown in the upper left corner of the figure. The shaded areas illustrate the positive, the empty areas the negative zones; fine solid lines in each zone represent isopotential lines for each $0.5 \mathrm{mV}$, and the broken line stands for the zero potential (for explanation: see text).

tion (phase I) in all of the Type I maps lead us suggest that Type I represents the normal conduction in the main fascicule of the right bundle branch since in these cases the characteristic potential distribution of the septal activation and right epicardial breakthrough was maintained. In the cases of Type II maps, at the onset of ventricular activation the early excitation wavefront was directed to the apical region of the right ventricle and the right epicardial breakthrough occurred at the same site. In the time instant of the latter event the multiple maxima corresponding to the right ventricle suggested a conduction defect in the right bundle branch too. In the surface maps of our 2 patients classified as Type III the initial direction of ventricular activation was directed towards the posterior-inferior part of the interventricular septum and the ventricular breakthrough was seen to arrive from the lateral surface of the right ventricle. All these abnormal findings suggest an abnormal conduction in the Types II and III maps also characterizing a different degree of damage in the right bundle branch.

All these conduction disturbances might be explained by the ramifications of the right bundle branch. According to Lev ${ }^{7)}$ the right bundle branch divides into anterior, septal and diaphragmatic ramifications and 
theoretically the damage of 1 or 2 groups of these fibers may cause such conduction disturbances observed in our different types. The interruption of conduction in the hypothetical anterior division in which the excitation is conducted by false tendons to the right ventricular free wall may correspond to the Type II maps and the disturbed conduction both in the anterior and septal ramifications, may lead to a right ventricular excitation spread which was reflected in the Type III maps. Obviously we are aware that different interpretations of these multiple conduction defects are quite probable since the genesis of surface potential distribution depends on different factors. One has also to take into account that in the site of different subdivisions the false tendons and terminal Purkinje fibres receive an indirect transmyocardial blood supply ${ }^{8)}$ and the ischemic lesions of specialized conducting fibres also involve a certain amount of damage to the working myocardium.

The correct analysis of these combined conduction disturbances has to be based on direct measurements and/or postmortem histological examinations which are not yet available.

The pathways of the left ventricular activation (phase II and phase III) were almost the same in all cases except for the Type IV map. van Dam has pointed out in his experimental activation study ${ }^{2}$ that in the presence of chronic LBBB, phase II shows a pure myocardial conduction instead of activation of the peripheral parts of Purkinje's plexus and this direction of ac-

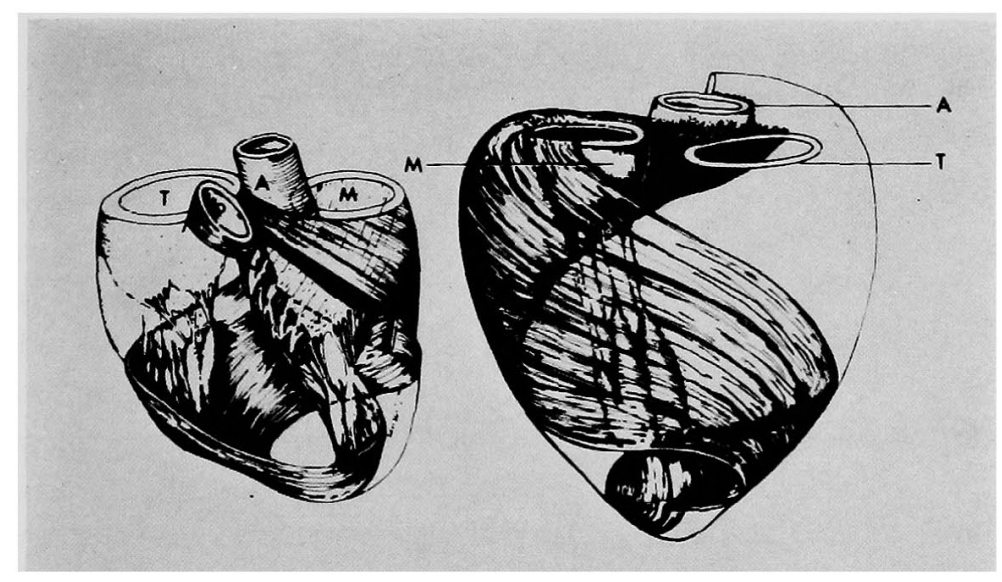

Fig. 10. Superficial bulbo-spiral muscle as seen from front (left side of figure) and from back (right side of figure) of heart. The direction of this subepicardial muscle layer is through the apex of the heart and in a crescentshaped path travels through the mid-posterior, posterolateral surface of the left ventricle terminating in the anterobasal area. $T$ : tricuspid valve; $P$ : pulmonary artery; A: aorta; $\mathrm{M}$ : mitral valve. (After Robb and Robb: Am Heart J 23: 455, 1942, slightly modified.) 
tivation is tangential to the epicardial surface thereby resulting in crescentshaped activation waves. Based on our results, we suggest that the myocardial activation in the left ventricle is determined by the direction of the subepicardial muscle layer of the left ventricle (Fig. 10), which is running through the apex of the heart (vertex) and in a crescent-shaped path travels through the mid-posterior, posterolateral surface of the left ventricle terminating in the anterobasal area. ${ }^{14)}$ However, during phase III, the participation of the Purkinje system in the terminal activation events ${ }^{11)}$ may also play a role, taking into consideration of the multiple maxima observed in the anterobasal region. The finding of a maximum or maxima in the anterobasal region during the late ventricular excitation is not contrary to the activation study of van $\mathrm{Dam}^{2)}$ in that he observed a late antero-lateral activation. In one of his cases he demonstrated a late basal-anteroseptal excitation interpreted as being due to a scar caused by the incision to produce a LBBB. Furthermore, a simulation study by Okajima et al ${ }^{13)}$ using a ventricular model has shown a late anterobasal excitation in the case of anterior subendocardial infarction, thus without the presence of anteroseptal Purkinje network, which is comparable to the lack of anterior-superior division of left bundle branch.

This late activation of the left ventricular anterior surface which might

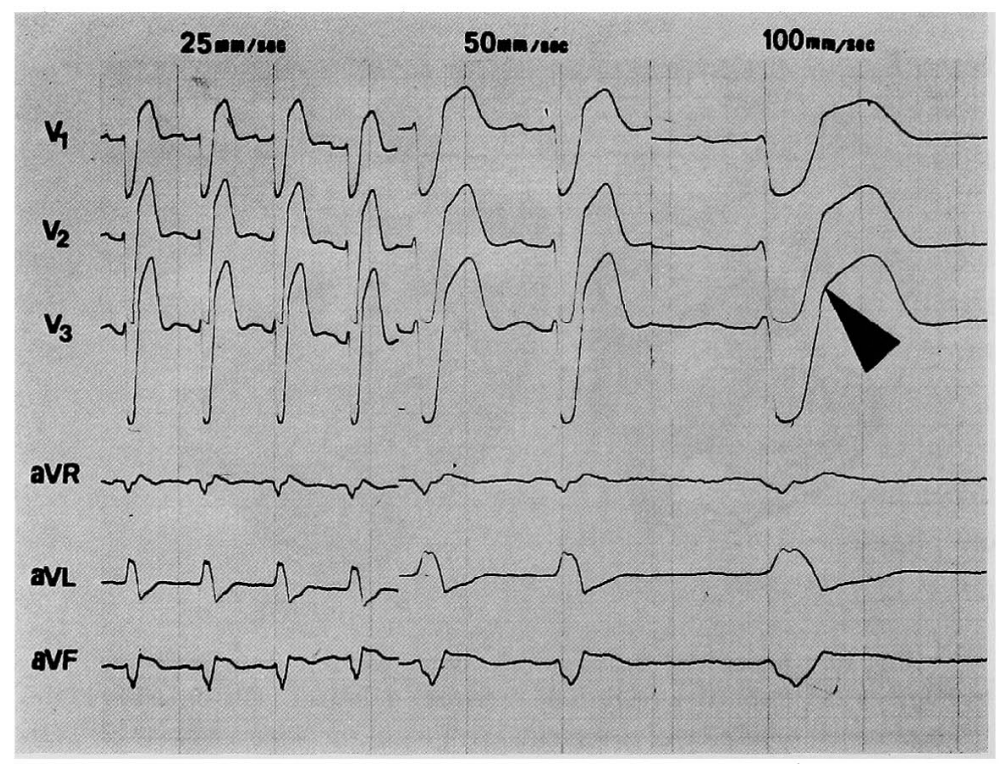

Fig. 11. Simultaneous representation of $V_{1}-V_{3}$ precordial and aVR, aVL, aVF unipolar leads with different paper-speeds. The arrow indicates the end of upright $\mathrm{S}$ wave which coincides in time with the terminal deflections of the QRS complex in the unipolar leads. 


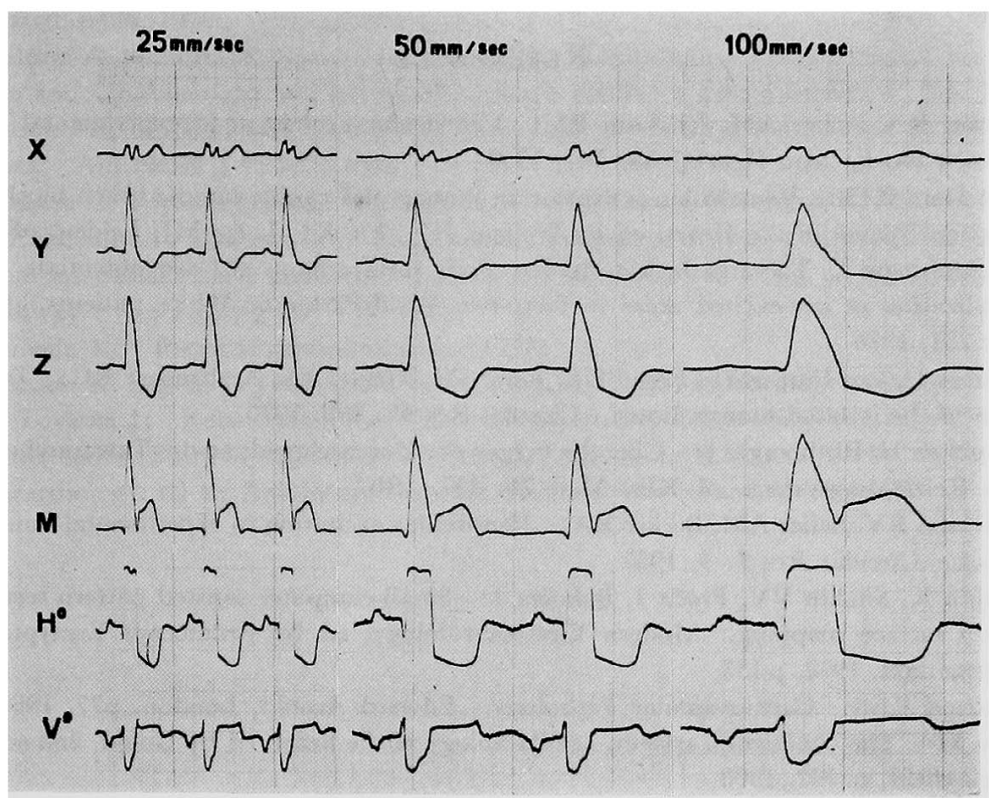

Fig. 12. $\mathrm{Y}, \mathrm{X}, \mathrm{Z}$ orthogonal Frank leads, the spatial magnitude (M), the azimuth $\left(\mathrm{H}^{\circ}\right)$, and elevation $\left(\mathrm{V}^{\circ}\right)$ angles recorded in continuous graphical form with different paper-speeds. The terminal activation vectors are directed anteriorly and upward. These late terminal events are characteristically represented both in the spatial magnitude (M) as a second deflection following a minimum and also in the angle traces $\left(\mathrm{H}^{\circ}\right.$ and $\left.\mathrm{V}^{\circ}\right)$. The azimuth $\left(\mathrm{H}^{\circ}\right)$ unambiguously shows that this terminal event belongs to the depolarization.

also be considered in the 12-lead ECG and X, Y, Z orthogonal leads (Figs. 11 and 12) in the cases of LBBB, may also explain the diagnostic difficulties of anteroseptal myocardial infarction in the presence of LBBB since the signs of myocardial necrosis in the $\mathrm{V}_{1}-\mathrm{V}_{3}$ precordial leads of conventional ECG must be hidden not in the early part of the QRS complex, but in the terminal portion of the upright $S$ wave.

The Type IV surface pattern of LBBB cannot be explained by the assumption made in the previous types. The activation of both ventricles seems to be symmetric, the excitation travels through the posterior walls and terminates on the posteroseptal and right antero-lateral surfaces. This surface map pattern, on the one hand, may indicate a considerable right ventricular conduction defect, and on the other the lack of terminal anterobasal activation, i.e. a chronic anterior myocardial infarction. A similar surface map pattern of LBBB associated with myocardial infarction has been observed by Yamada. ${ }^{26)}$ 


\section{REFERENCES}

1. Becker RA, Acher AM, Erickson RV: Ventricular excitation in experimental left bundle branch block. Am Heart J 55: 547, 1958

2. van Dam RTh: Ventricular activation in human and canine bundle brach block. in Conduction System of the Heart, ed by Wellens HJJ, Lie KI, Janse MJ, Leiden, p377, 1976

3. de Ambroggi L, Taccardi B, Macchi E: Body surface maps of heart potentials. Tentative localization of pre-excited areas in forty-two Wolff-Parkinson-White patients. Circulation 54: 251,1976

4. Durrer D, van Dam RTh, Freud GE, Janse JM, Meijler FL, Arzbaecher RC: Total excitation of the isolated human heart. Circulat Res 41: 899, 1970

5. Eppinger $\mathrm{H}$, Rothberger J: Uiber die Folgen der Durchschneidung der Tawaraschen Schenkel des Reizleitungsystem. Z Klin Med 71: 157, 1910

6. Erickson RV, Scher AM, Becker RA: Ventricular excitation in experimental bundle-branch block. Circulat Res 5: 5, 1957

7. Hajdu K, Shakin VV, Préda I, Bukosza I: Small-computer assisted pattern recognition in body surface mapping. Modern Electrocardiology, ed by Antalóczy, Excerpta Medica, Amsterdam, 1978, p 133

8. Hudson REB: Cardiovascular Pathology. Edward Arnold, London, p77, 1965

9. Lev M: The conduction system. in Pathology of the heart, ed by Gould, 2nd ed, Thomas, Springfield, p. 132, 1960

10. Lewis T: Certain physical signs of myocardial involvment. Brit Med J 7: 484, 1913

11. Myerburg RJ, Gelband H, Castellanos A, Nilson K, Sung RJ, Besset AL: Electrophysioıgy of endocardial intraventricular condution. The role and function of the specialized conducting system. in Conduction System of the Heart, ed by Wellens HJJ, Lie KI, Janse MJ, Leiden, p336, 1976

12. Niimi N, Sugiyama S, Wada $M$, Sugenoya J, Oguri $H$, Toxama J, Okajima M, Yamada K: Genesis of body surface potential distribution in right bundle branch block. J Electrocardiol 10: 257,1977

13. Okajima M, Ishikawa T, Niimi N, Koike Y, Toyoma J, Yamada K: Differences in isopotential surface map between transmural and non-transmural myocardial infarction. in Coeur et l'Esprit, ed by Reuse-Blom S, Editions Université de Bruxelles, p847, 1977

14. Robb JS, Robb LR: The normal heart. Am Heart J 23: 455, 1942

15. Rodriguez ML, Sodi-Pallares D: The mechanism of complete and incomplete bundle branch block. Am Heart J 44: 715, 1952

16. Schamroth L: The Electrocardiology of Coronary Artery Disease. Blackwell, Oxford, p83, 1975

17. Spach MS, Barr RC, Lanning CF, Tucek PC: Origin of body surface QRS and T wave potentials from epicardial potential distributions in the intact chimpanzee. Circulation 55: 268,1977

18. Sugenoya J, Sugijama S, Wada M, Niimi N, Oguri H, Toyama J, Yamada K: Body surface potential distribution following the production of right bundle branch block in dogs. Effects of breakthrough and right ventricular excitation on the body surface potentials. Girculation 55: 49,1977

19. Taccardi B: Distribution of heart potentials on dog's thoracic surface. Circulat Res 11: 862,1962

20. Taccardi B: Distribution of heart potentials on the thoracic surface of normal human subjects. Circulat Res 12: 341, 1963

21. Taccardi B, de Ambroggi L, Riva D: Chest maps of heart potentials in right bundle branch block. J Electrocardiol 2: 109, 1969

22. Taccardi $\mathbf{B}$, de Ambroggi L, Viganotti C: Body surface mapping of heart potentials. in The Theoretical Basis of Electrocardiology, ed by Nelson CV, Geselowitz D, Clarendon Press, 
Oxford, p436, 1976

23. Waltson A, Boineau JP, Spach MS, Ayers CP: Relationship between ventricular depolarisation and QRS in right and left bundle branch block. J Electrocardiol 1: 155, 1968

24. Wilson FN, Macleod AG, Barker PS: The order of ventricular excitation in bundle branch block. Am Heart J 7: 305, 1932

25. Yamada K, Toyama J, Wada M, Sugiyama S, Sugenoya J, Toyohima H, Mizuno Y, Sotohata I, Kobayashi T, Okajima M: Body surface isopotential mapping in Wolff-Parkinson-White syndrome: noninvasive method to determine the localization of the accesory atrioventricular pathway. Am Heart J 90: 721, 1975

26. Yamada K: Personal communication (1977)

27. Yamada K, Sugenoya J, Ohno M, Nakashima M, Ohishi P, Horiba M, Nagaya T, Nishijima $\mathrm{K}$, Toyama J: Relationship between body surface isopotential map and activation sequence of the canine heart in experimentally induced right bundle branch block. in Modern Electrocardiology, ed by Antalóczy, Excerpta Medica, Amsterdam, 1978, p 109 